\title{
Use of Simulation in Nursing Education: Initial Experiences on a European Union Lifelong Learning Programme - Leonardo da Vinci Project
}

\author{
Fusun Terzioglu ${ }^{1}$, Zahide Tuna ${ }^{1}$, Sergul Duygulu ${ }^{1,}$, Handan Boztepe ${ }^{1}$, Sevgisun Kapucu ${ }^{1}$, Leyla Ozdemir ${ }^{1}$, Nuran \\ Akdemir $^{1}$, Deniz Kocoglu ${ }^{2}$, Guillaume Alinier ${ }^{3}$ \& Filippo Festini ${ }^{4}$ \\ ${ }^{1}$ Faculty of Nursing, Hacettepe University, 06100 Samanpazari, Ankara, Turkey \\ ${ }^{2}$ Nursing Department, School of Health, Selcuk University, Konya, Turkey \\ ${ }^{3}$ University of Hertfordshire, Hatfield, UK \\ ${ }^{4}$ Nursing Department, University of Florence, Florence, Italy \\ *Faculty of Nursing, Hacettepe University, 06100 Samanpazari, Ankara, Turkey \\ Tel: 90-312-305-1580 E-mail: sduygulu@hacettepe.edu.tr
}

Received: November 19, 2012

Accepted: December 11, 2012

Online Published: January 7, 2013

doi:10.5430/jct.v2n1p34

URL: http://dx.doi.org/10.5430/jct.v2n1p34

\begin{abstract}
Aim: The aim of this paper is to share the initial experiences on a European Union (EU) Lifelong Learning Programme Leonardo Da Vinci Transfer of Innovation Project related to the use of simulation-based learning with nursing students from Turkey. The project started at the end of the 2010 involving 7 partners from 3 different countries including Turkey, England, and Italy.

Methods: This project is divided into 7 work packages (WP). In this paper, experiences from the first three WPs (WP1: Preparation and dissemination of the project. WP2: Regulation of the project management. WP3: Development of the evaluation tools used to evaluate the impact of the innovative practice within the coordinating partner's institution) are shared.

Results: In the WP1 and WP2: the kick-off meeting was organized in Turkey, the coordinating partner's country. During the meeting project-related events were planned and the steering committee of the project was formed. A strong team spirit within the partnership was established. For the dissemination of the project, a poster and flier of the project were prepared and placed on corporate boards visible to students and teaching staff and put on the partners' institutional websites. Regular bulletins of the project were also prepared and posted on the project website. In the WP3, student data sheet, items for students' satisfaction questionnaire and confidence scale were created based on the literature. Trauma patient scenarios (abdominal trauma, thoracic trauma, pelvic fracture and traumatic amputation) were created to test the target group's knowledge. Ethical approval was obtained from the coordinating partner institution. A pilot study to test the cases was conducted. Following the pilot study, the final version of the student data sheet and scenario cases was created. The second meeting was organized in Italy. In this meeting, the results of the pilot study, the scenario cases, and the Patient Intervention Self Confidence /Competence Scale were evaluated.

Conclusion: The work on this EU project is still in progress. Considering that learning from experience is an important part of nursing education, sharing experiences on such a project related to using simulation as an innovative teaching strategy in nursing education in Turkey should provide an example to others who want to develop other EU projects in nursing education.
\end{abstract}

Keywords: patient simulation; nursing education; technology transfer; innovation; nursing student

\section{Introduction}

In practice-based healthcare professions, methods of teaching and learning focus on enabling students to assimilate clinical knowledge and skills. Nursing students need to learn how to apply classroom learning in the clinical context 
(Cant \& Cooper, 2010). Clinical simulation may well be an educational strategy for achievement of these outcomes as it uses active learning (Cioffi, 2001) applicable to nursing (National Council of State Boards of Nursing, 2005) and has been widely incorporated into international undergraduate nursing curricula (Berrega, 2011, McKenna et al., 2007, Murray et al., 2008).

There are numerous studies showing the positive impact of using simulation to the clinical training of nurses (Alinier $e t$ al., 2006, Bremner et al., 2006, Decker et al., 2008, Lambton et al., 2008). Although the technology and pedagogy around simulation have progressed significantly, it has not been the case everywhere such as in Turkey. In the lights of these developments in nursing education Hacettepe University Faculty of Health Sciences, thought support from the EU Lifelong Learning Programme Leonardo Da Vinci Transfer of Innovation program by partnering with other institutions for a project called "Use of Simulation: An Educational Strategy to Develop Clinically Competent Nurses (US:ESDCCN)" which started in December 2010 (2010-1-TR1-LEO05-16726). Seven partners from three different countries including Turkey, England, and Italy were involved in the project. The US:ESDCCN project aimed to take advantage of some countries' experience (England) to establish simulation practice in Turkey and inform other partners (from Italy and Turkey). The project will be contributing to this EU program's objectives as it supports improvements in quality and innovation in vocational education and training systems, institutions, and practices. It will also improve the quality and increase the volume of co-operation between institutions providing learning opportunities, companies, social partners, and other relevant bodies throughout Europe. Another aim was "to support the development of innovative Information and Communications Technology (ICT)-based content, services, pedagogies and practice for lifelong learning". Development of new policies and strategies in nursing education in Europe was another expected contribution of this project.

In this paper the initial experiences on this US:ESDCCN project are shared.

\section{Using simulation in nursing education as an educational strategy}

Educating nurses to provide competent care in today's health care environment is becoming increasingly challenging because of the need to care for complex patients in complex care environments (Decker et al., 2008, Rhodes \& Curran, 2005). Nurse educators are increasingly challenged to find adequate clinical experiences to prepare students for such practice demands (Rhodes \& Curran, 2005). There is a recognized gap between clinical practice and the theory provided in nursing schools which can be addressed by using simulation (Alinier et al., 2006). Simulation training is a recommended strategy to teach safe clinical practice, because initial learning for healthcare professionals in a real patient setting is hindered by changes in resources, such as shorter length of patient stay, higher patient acuity, nursing staff shortages, and a greater concern and emphasis on the prevention of medical errors (Rauen, 2004).

Simulation allows learners to gain experience that may not be available in the immediate clinical area, but will be part of their practice in the real world of healthcare. Unlike the traditional classroom setting, a simulated situation allows the learner to think spontaneously and actively rather than passively. Through simulation, a predictable environment can be created to allow healthcare providers to practice under realistic conditions in "real time" using actual clinical supplies (Broussard et al., 2009).

Simulation allows multiple learning objectives to be taught in a realistic clinical environment without harming patients (Radhakrishnan et al., 2007). Students are exposed to a realistic situation that could be community or hospital based and will need to combine their assessment and clinical decision-making skills with communication, teamwork and management to care for the simulated patient(s) or patient simulator. Following the simulation, the learners are able to reflect on their performances with a facilitator as part of the debriefing process. By discussing their areas of strength and development in line with current evidence, they can begin to improve their competence, and ultimately, confidence (Berregan, 2011, Wilford \& Doyle, 2006).

It is possible for students to develop and maintain their confidence when exposed to authentic and challenging simulated learning situations (Lambton et al., 2008, Moule, 2008, Reilly \& Spratt, 2007). Simulation is becoming increasingly common in a variety of educational settings, including healthcare staff development programs, medical schools, and nursing schools (Bremner et al., 2006). It has been encouraged in the Institute of Medicine's 1999 report (Kohn et al., 1999) to train novice as well as experienced practitioners in different disciplines (Issenberg et al., 1999). 


\section{Introduction of the US:ESDCCN project}

The aim of the US:ESDCCN project was to transfer innovative simulation-based training practices, improve vocational training methodologies, collaborate and transfer knowledge, experience and technology between EU Member States. Seven partners from three different countries including Turkey, England, and Italy are involved in the project. The project duration is 24 months.

The project focuses on the facilitation of scenario-based simulation for nursing students around the care of trauma patients. The assessment and care of trauma patients requires nurses to think critically and act rapidly, hence requiring to develop a high level of clinical judgment. Trauma patient care includes various nursing interventions such as rapid assessment of the patient's condition, establishing venous access, protecting vital organs; and maintaining basic life functions.

At the end of the project, it is expected that recommendations regarding the best practices for nurse educators in the use of the trauma low fidelity and scenario-based patient simulation training will be made particularly for the acquisition of clinical skills for the novice practitioner. It is also expected to improve patient safety in today's health care environment, particularly in countries where the use of the scenario-based patient simulation is currently underdeveloped.

The project process will allow the partners to formulate and share examples of good practice as a basis for future development both within the partnership and for a wider stakeholder base. When achieved, these project's aims and objectives will contribute to develop the quality and attractiveness of Vocational Education and Training (VET) systems and practices. In this instance, it is focusing on nursing education, but it is directly applicable to many other healthcare disciplines with a VET system. The project outcomes will not only result in supporting the partner institutions to incorporate simulation in their nursing curricula but although encourage other nursing schools from across the EU to use simulation as a teaching strategy.

\subsection{Performed tasks on US:ESDCCN}

The project is divided into 7 work packages (WP), the experience of first three WPs is discussed in this paper.

\subsubsection{For the WP 1: Dissemination of the project results}

This WP included the dissemination of the project and the project's results. It covered ongoing activities over the entire duration of the project.

For the dissemination of the project in WP 1; a poster of the project was prepared and handed out to the related institutions. A brief outline presenting the project was placed on the website of each partner institution. In addition, a project website (www.ldvusin.org) was built to provide an open field for communication between the partnership, the potential users, and related institutions. Additional means of communication used by the partners include a secure area on the website and Skype. Project partners publish project related activities, information, announcements, and web link to their institutions. Bulletins of the US:ESDCCN project (volume 1, issue 1 and 2, 2011) were prepared (in Turkish, English and Italian) and published on the website of the project. The project was presented at the Annual Meeting of the Society in Europe for Simulation Applied to Medicine-SESAM 2011 (http://sesam.iavante.es/index.php) in Spain and at various institutional seminars in partners' institutions. A publication is also in preparation to report findings from the pilot study and a Gantt Chart was created and shared with the project partners.

\subsubsection{WP 2: Regulation of project management}

This WP included the overall management, quality control, and communication aspects of the project. At the onset of the project, it included the organization of a meeting to discuss the project management and responsibilities of each partner, setting up a steering committee including a member from each partner institution to ensure compliance with the quality criteria and charging an evaluator with examining the process of the project. This kick-off meeting was organized in the coordinator partner's country (Turkey). In this meeting, the project's work program was introduced to the partners and the project management discussed through group discussion. During the meeting future events were planned and the steering committee of project was formed. In this process all contractual and administrative issues of the project were managed. Since the project partnership is important for achieving the project objectives, a strong team spirit within the partnership was established.

\subsubsection{WP 3: Identification of the needs of the target group}

This WP included the creation of a demographic questionnaire and four written scenario cases about trauma patients (paper simulation) (Alinier, 2007). It also included reviewing the literature to prepare a student satisfaction questionnaire and validated scale to determine students' confidence which will be used post-simulation exposure at the 
end of project to evaluate the perceived effectiveness of scenario-based simulation as a teaching strategy (Abdo \& Ravert, 2006, Alinier et al., 2004, Bambini et al,. 2007, Beyca \& Kobokovich, 2004, Feingold et al., 2004, Levett-Jones et al., 2011, Mole and McLaffery, 2004, Schoening, 2006). There were study results that support the use of simulation scenarios throughout the undergraduate curriculum because it can be beneficial to enhance student's confidence regarding patient care decisions (Bambini et al., 2007, Beyca \& Kobokovich, 2004).

Some key phases of this WP include:

1) Conduction of a pilot study for testing the prepared scenarios and data sheets (student satisfaction and student self-confidence scale).

2) Analysis of the pilot study results.

3) Presentation of the results of the pilot study at national or international conferences.

4) Publication of the results of the pilot study in national or international journals.

5) Organization of a two-day meeting in February 2012 in Italy.

For the identification of the needs of the target group in WP 3; A literature review was performed for post-simulation experience questionnaires evaluating the students' satisfaction and the students' confidence. A demographic questionnaire and four scenario cases about trauma patients (abdominal trauma, thoracic trauma, pelvic fracture, and traumatic amputation) were created to test the pilot target group's knowledge.

The cases (abdominal trauma, thoracic trauma, pelvic fracture, and traumatic amputation) developed by the faculty focused on the care of a trauma patient. Aims and learning objectives were developed prior to the cases and used as a reference to design the trauma cases. Each case included multiple choice questions, open-ended questions to measure students' cognitive skills. Abdominal trauma case is given below (see Text Box 1).

An ethical approval from the coordinating partner institution was obtained and a pilot study (paper simulation) to test the demographic questionnaire and four written scenario cases was conducted. A report based on the analysis of the pilot study was prepared. According to pilot study results, over fifty percent of the students answered the multiple choice questions correctly. Overall, the students' ability of identifying and listing the correct diagnosis and interventions in the expected priority order was low. Following the pilot study, final versions of the four trauma scenarios were created. Modifications were made to the scenario format as per a published scenario template (Alinier, 2011). The meeting was organized by the University of Florence in Italy. In this meeting, results of the pilot study were evaluated and a group discussion was held to identify the educational needs of the participating students. Translation of demographic questionnaire and written scenario cases from Turkish into English was done. In addition Patient Intervention Self Confidence/Competence Scale items were discussed during this meeting by partners. Following this meeting, content validity of this scale was evaluated by seven experts. After their recommendations, the students' satisfaction questionnaire and students' confidence questionnaire were finalized for validity and reliability study. The number of items was 18 assessed with a five-point Likert scale. The validity and reliability study was conducted with 205 medical students from one university in Turkey that used simulation as a teaching strategy to develop medical students' competence and confidence on patient interventions. Exploratory Factor Analysis identified 3 factors explaining $60.9 \%$ of total variances. These three factors were classified as clinical implementation (11 items), psychosocial support (4 items) and knowledge of health care system (3 items). All items had factor loadings more than 0.40 . Cronbach's $\alpha$ for the entire scale was 0.91 , with subscales ranging from 0.80 to 0.94 . When all of these values were taken into account, the "Patient Intervention Self Confidence / Competence Scale" was found reliable and valid for measuring health care students' self confidence and competence on patient interventions.

Text Box 1: Abdominal Trauma Case

Aim: To ensure the continuation of the vital functions of the patient by using the appropriate nursing interventions as soon as possible.

\section{Case Objectives:}

The student will be able to:

- define anatomical regions and organs of the abdomen

- $\quad$ analyze the observed physical examination findings of patients with abdominal trauma

- evaluate abdominal trauma that is blunt or penetrating

- identify at least 10 nursing diagnosis of patient with abdominal trauma 
- $\quad$ explain at least 15 nursing interventions applied to patients with abdominal trauma.

A 28-year-old female patient is brought to the emergency department in a taxi by her two neighbors 30 minutes after having been stabbed by her husband in her abdomen. The unconscious patient is hypotensive, tachycardic and has intestinal evisceration. The following are the findings on the basis of the patient's initial physical examination in the emergency department.

\section{Vital signs:}

Respiratory rate: $28 / \mathrm{min}$.

Pulse: $144 / \mathrm{min}$.

Blood pressure: $55 / 20 \mathrm{mmHg}$

Temperature: $35,8^{\circ} \mathrm{C}$

Pain: It could not be assessed due to the patient being unconscious.

Head and Neck: Normal appearance

Respiratory system:

Airway: Open O2Sat: 90

...

\section{Cardiovascular system:}

S1(+), S2(+), Rhythm: Sinus tachycardia

...

\section{Gastrointestinal system:}

Abdomen: Bowel evisceration in the lower left quadrant ...

\section{Neurological system:}

Consciousness: Not responding

Pupils: Equal and isochoric, IR +/+

Glasgow Coma Score: 7

\section{Musculoskeletal system:}

Normal appearance

Skin:

Color: pale and cold

$\cdots$

\section{Appearance:}

A $15 \mathrm{~cm}$ wide injury with smooth edges and an evisceration likely created with stab to the left lower abdominal quadrant. The wound is about $2 \mathrm{~cm}$ wide with smooth-edges and bleeding likely created by the $5 \mathrm{~cm}$ stab in the lumbar region, right and lateral to the umbilicus. $2 \mathrm{~cm}$ wide, smooth-edged wound without bleeding in the right hypocondirum. There is no other visible injury of the patient.

History/background:

Chronic disease: No

Allergy: None

...

\section{Laboratory Results:}

CBC:

$\mathrm{Hb}: 8.1 \mathrm{gr} / \mathrm{dl}$

\section{Family History:}

Mother: Hypertension, Sibling: Hemophilia $\cdots$

$\underline{A B G:}$

Glucose: $102 \mathrm{mg} / \mathrm{dL} \quad \mathrm{pH}: \quad 7.33$ 


\section{Diagnostic Tests: $\cdots$ \\ Physician's Order: \\ 1) Tetanus prophylaxis \\ 2) No oral intake \\ 3) $100 \mathrm{cc} / \mathrm{h}$ Normal saline \\ 4) $\ldots$}

X-ray: Air-liquid areas in the abdomen. The appearance of the lungs is normal.

\section{Sample Case Multiple Choice Questions:}

1. The priority level and organ injury of this patient are matched with triage in the emergency department. Please circle the correct answer.
a) Level 1 - Bowels
b) Level 2 - Liver
c) Level 3 - Ovaries
d) Level 4 - Spleen

Determine the top 10 nursing diagnoses for this patient in order of urgency.

\section{Nursing Diagnosis:}

1. Lack of fluid volume due to active bleeding or loss of fluid

2. Decrease in cardiac output due to active bleeding or loss of fluid

3. Impaired tissue perfusion (cerebral) due to active bleeding or loss of fluid

4. $\quad \ldots$

Write 15 nursing interventions you have planned for this patient in decreasing priority order.

\section{Nursing Interventions:}

1. Assess airway for obstruction (A).

2. Maintain open airway

3. Assess (B) for breathing.

4. .

\subsection{Difficulties in the US:ESDCCN project process}

There have been positive experiences as well as some difficulties in the project such as the withdrawal of partner 5 (P5), the Turkish Republic Ministry of Health Ankara Provincial Health Directorate. To overcome this change; the responsibilities of P5 was shared among the Hacettepe University Faculty of Health Sciences Nursing Department (P0), the University of Hertfordshire Higher Education Corporation (P1), the University of Florence Department of Sciences of Women's and Children's Health, Laboratory of Nursing Science (P5), and the Association of Research and Development in Nursing (P2).

There was another challenging situation in the US:ESDCCN project process. Following literature review for post-simulation evaluation of the students' satisfaction and confidence, The Turkish validity studies of the Student Satisfaction and Self-Confidence in Learning Scale developed by the National League for Nursing (NLN) was done. But, the content validity of the scale was not found to be appropriate for the Turkish nursing students by the experts. Thus, a new scale for post-simulation evaluation of Turkish students' self confidence /competence had to be developed. 


\section{Conclusion}

Learning from experience is an important part of nursing education. To share experiences of USESDCCN as an EU project should provide an example for others who want to develop and embark into an EU project in nursing education. We accept that we have experienced some difficulties in the project process, but the process for three work packages was ultimately extremely beneficial. Given the escalating pressures in practice settings and increasing technological advances, it is likely that simulation will gain further popularity and wider adoption of both high-fidelity, and online virtual simulation will increase (Moule, 2011). Therefore, it is expected that we will be able to recommend best practices and competency for nurse educators in the use of the scenario-based patient simulation training, particularly as it applies to the acquisition of clinical skills for the novice practitioner. This enhanced educational approach is expected to improve patient safety in today's health care environment, particularly in countries where the scenario-based patient simulation is currently underdeveloped.

\section{References}

Abdo A., \& Ravert, P. (2006). Student satisfaction with Simulation Experiences. Clinical Simulation in Nursing, 2(1), 13-16. http://dx.doi.org/10.1016/j.ecns.2009.05.009

Alinier, G. (2007). A typology of educationally focused medical simulation tools. Medical Teacher, 29, $243-250$. http://dx.doi.org/10.1080/01421590701551185

Alinier, G. (2011). Developing high-fidelity health care simulation scenarios: a guide for educators and professionals. Simulation \& Gaming, 42(1), 9-26. http://dx.doi.org/10.1177/1046878109355683

Alinier, G., Hunt, B., Gordon, R., \& Harwood, C. (2006). Effectiveness of intermediate-fidelity simulation training technology in undergraduate nursing education. Journal of Advanced Nursing, 54(3), 359-369. http://dx.doi.org/10.1111/j.1365-2648.2006.03810.x

Alinier, G., Hunt, W.B., \& Gordon, R. (2004). Determining the value of simulation in nurse education: study design and initial results. Nurse Education in Practice, 4, 200-207. http://dx.doi.org/10.1016/S1471-5953(03)00066-0

Bambini, D., Washburn, J., \& Perkins, R. (2009). Outcomes of clinical simulation for novice nursing students: Communication, confidence, clinical judgment. Nursing Education Perspectives, 30(2), 79-82.

Berregan, L. (2011). Simulation: An effective pedagogical approach for nursing? Nurse Education Today, 31(7), 660-663. http://dx.doi.org/10.1016/j.nedt.2011.01.019

Beyea, S.C., \& Kobokovich, L.J. (2004). Human patient simulator: a teaching strategy. AORN J, 80(4), 738-42. http://dx.doi.org/10.1016/S0001-2092(06)61329-X

Bremner, M.N., Adduddel, K., Bennett, D.N., \& VanGeest, J.B. (2006). The use of human patient simulators best practice with novice nursing student. Nurse Educator, 31(4), 170-174. http://dx.doi.org/10.1097/00006223-200607000-00011

Broussard, L., Myers, R., \& Lemoine, J. (2009). Preparing pediatric nurses: the role of simulation-based learning. Compr Pediatr Nurs, 32(1), 4-15. http://dx.doi.org/10.1080/01460860802610178

Cant, R.P., \& Cooper, S.J. (2010). Simulation-based learning in nurse education: systematic review. Journal of Advanced Nursing, 66(1), 3-15. http://dx.doi.org/10.1111/j.1365-2648.2009.05240.x

Cioffi, J. (2001). A study of the use of past experiences in clinical decision making in emergency situations. International Journal of Nursing Studies, 38, 591-599. http://dx.doi.org/10.1016/S0020-7489(00)00096-1

Decker, S., Sportsman, S., Puetz, L., \& Billings, L. (2008). The evolution of simulation and its contribution to competency. The Journal of Continuing Education in Nursing, 39(2), 74-80. http://dx.doi.org/10.3928/00220124-20080201-06

Feingold, C.E., Calaluce, M., \& Kallen, M.A. (2004). Computerized patient model and simulated clinical experiences: Evaluation with baccalaureate nursing students. Journal of Nursing Education, 43(4), 156-163.

Issenberg, S.B., McGaghie, W.C., Hart, I.R., Mayer, J.W., Felner, J.M., \& Petrusa, E.R. et al. (1999). Simulation technology for health care professional skills training and assessment. JAMA, 282(2), 861-866. http://dx.doi.org/10.1001/jama.282.9.861

Kohn, L.T., Corrigan, J.M., \& Donalson, M.S. (1999). To Err is Human: Building a Safer Health System. Washington DC:National Academy Press. 
Lambton, J., O’Neill, S.P., \& Dudum, T. (2008). Simulation as a strategy to teach clinical pediatrics within a nursing curriculum. Clinical Simulation in Nursing, 4(3), 79-87. http://dx.doi.org/10.1016/j.ecns.2008.08.001

Levett-Jones, T., McCoy, M., Lapkin, S., Noble, D., Hoffman, K., Dempsey, J., Arthur, C., \& Roche, J. (2011). The development and psychometric testing of the Satisfaction with Simulation Experience Scale. Nurse Education Today, 31(7), 705-10. http://dx.doi.org/10.1016/j.nedt.2011.01.004

McKenna, L., French, J., Newton, J., \& Cross, W. (2007). Prepare nurses for the future: Identify use of simulation, and more appropriate and timely clinical placement to increase clinical competence and undergraduate positions; Final report of key activities for department of human services nurse policy branch. Melbourne: Monash University Victoria Australia.

Mole, L.J., \& McLaffery, I.H.R. (2004). Evaluating a simulated ward exercise for third year student nurses. Nurse Education in Practice, 4, 91-99. http://dx.doi.org/10.1016/S1471-5953(03)00031-3

Moule, P. (2008). Student experiences and mentor views of the use of simulation for learning. Nurse Education Today, 28, 790-797. http://dx.doi.org/10.1016/j.nedt.2008.03.007

Moule, P. (2011). Simulation in nurse education: Past, present and future. Nurse Education Today, 31(7), 645-46.

Murray, C., Grant, M.J., Howarth, M.L., \& Leigh, J. (2008). The use of simulation as a teaching and learning approach to support practice learning. Nurse Education in Practice, 8(1), 5-8. http://dx.doi.org/10.1016/j.nepr.2007.08.001

National Council of State Boards of Nursing. (2005). Clinical instruction in pre-licensure nursing programs. Chicago, IL, USA: NCSBN.

Nehring, W.M. (2008). U.S. boards of nursing and the use of high fidelity patient simulators in nursing education. Journal of Professional Nursing, 24(2), 109-117. http://dx.doi.org/10.1016/j.profnurs.2007.06.027

Radhakrishnan, K., Roche, J.P., \& Cunningham, H. (2007). Measuring clinical practice parameters with human patient simulation: a pilot study. Int J Nurs Educ Scholarship, 4(1), Article 8. http://dx.doi.org/10.2202/1548-923X.1307

Rauen, C.A. (2004). Simulation as a teaching strategy for nursing education and orientation in cardiac surgery. Crit Care Nurse, 24, 46-51.

Reilly. A., \& Spratt, C. (2007). The perceptions of undergraduate student nurses of high-fidelity simulation-based learning: A case report from the University of Tasmania. Nurse Education Today, 27, 542-550. http://dx.doi.org/10.1016/j.nedt.2006.08.015

Rhodes, L.M., \& Curran, C. (2005). Use of the human patient simulator to teach clinical judgment skills in a baccalaureate nursing program. Computer, Informatics, Nursing, 23(5), 256-262. http://dx.doi.org/10.1097/00024665-200509000-00009

Schoening, A.M. (2006). Simulated clinical experience: nursing students' perceptions and the educators' role. Nurse Educator, 31(6), 253-258. http://dx.doi.org/10.1097/00006223-200611000-00008

Wilford, A., \& Doyle, J.T. (2006). Integrating simulation training into the nursing curriculum. Br J Nurs., 15(17), 926-30. 